\title{
Interactive comment on "Technical Note: Equilibrium droplet size distributions in a turbulent cloud chamber with uniform supersaturation" by Steven K. Krueger
}

S. Krueger

steven.krueger@utah.edu

Received and published: 20 April 2020

The comment was uploaded in the form of a supplement: https://www.atmos-chem-phys-discuss.net/acp-2019-932/acp-2019-932-AC1supplement.pdf 2019. 